\title{
Effect of Fermentation Conditions and Plucking Standards of Tea Leaves on the Chemical Components and Sensory Quality of Fermented Juice
}

\author{
Ping Tang, ${ }^{1}$ Dan-Yu Shen, ${ }^{2}$ Yong-Quan Xu $\mathbb{D}^{3},{ }^{3}$ Xing-Cai Zhang $\mathbb{D}^{4,5}$ John Shi, ${ }^{6}$ \\ and Jun-Feng Yin ${ }^{3}{ }^{3}$ \\ ${ }^{1}$ Hangzhou Vocational \& Technical College, 68 Xueyuan Road, Hangzhou 310018, China \\ ${ }^{2}$ Institute of Subtropical Forestry, Chinese Academy of Forestry, 73 Daqiao Road, Fuyang, Hangzhou 311400, China \\ ${ }^{3}$ Tea Research Institute, Chinese Academy of Agricultural Sciences, 9 South Meiling Road, Hangzhou 310008, China \\ ${ }^{4}$ Materials Science Institute, Sun Yat-sen University, Guangzhou 510275, China \\ ${ }^{5}$ School of Engineering, Massachusetts Institute of Technology, Cambridge, MA 02139, USA \\ ${ }^{6}$ Guelph Food Research Center, Agriculture and Agri-Food Canada, Guelph, ON, Canada N1G 5C9
}

Correspondence should be addressed to Yong-Quan Xu; yqx33@126.com, Xing-Cai Zhang; xingcai@mit.edu, and Jun-Feng Yin; yinjf@tricaas.com

Received 27 October 2017; Revised 12 February 2018; Accepted 24 April 2018; Published 27 May 2018

Academic Editor: Davide Vione

Copyright (c) 2018 Ping Tang et al. This is an open access article distributed under the Creative Commons Attribution License, which permits unrestricted use, distribution, and reproduction in any medium, provided the original work is properly cited.

The effects of fermentation conditions (temperature, time, and $\mathrm{pH}$ ) and plucking standards (one leaf and a bud to four leaves and a bud) on the chemical components and sensory quality of the fermented juices processed from crushed fresh tea leaves were investigated. The results showed that optimum fermentation conditions that resulted in fermented juices of the best sensory quality and the highest content of TFs were a temperature of $35^{\circ} \mathrm{C}$, time duration of $75 \mathrm{~min}$, and $\mathrm{pH}$ 5.1. The fermented juices processed from new shoots with three leaves and a bud or four leaves and a bud afforded high overall acceptability and TF concentration. These differences arise because tea leaves with different plucking standards have different catechin content and enzyme activities. Fermented tea juice possessed higher concentrations of chemical components such as soluble solids, amino acids, and TFs and exhibited better sensory quality as compared to black tea infusion. The TF concentrations decreased as the $\mathrm{pH}$ of the fermenting juice increased, and the fermented juice showed the best overall acceptability. These results provide essential information for the improvement of the processing of black tea beverage by suggesting fermentation of fresh tea leaves as a better alternative to their infusion.

\section{Introduction}

Tea is one of the most popular beverages in the world. It is rich in antioxidants that help prevent various ailments such as cancer and heart diseases $[1,2]$. Fresh tea leaves can be processed into either green tea (nonfermented type), oolong tea (semifermented tea), or black tea (fermented tea). Black tea is consumed throughout the world and is known for its unique taste, briskness, and flavour. Catechins are the major biochemical constituents present in tea leaves, and they are oxidized to theaflavins (TFs) and thearubigins (TRs) during fermentation [3]. TFs are responsible for the astringency, brightness, colour, and briskness of black tea [4], and TRs contribute to the mouth feel (thickness) and colour of the tea [5]. Theaflavins are composed of theaflavin (TF), theaflavin3-gallate (TF-3-G), theaflavin-3' ${ }^{\prime}$-gallate (TF-3'-G), and theaflavin-3,3'-gallate (TFDG). The TFs are beneficial to human health [6].

Fermentation is a critical stage in the manufacturing of black tea during which catechins are oxidized to TFs and TRs by the action of polyphenol oxidase (PPO) and peroxidase (POD) enzymes [7]. The time [8], temperature [9], $\mathrm{pH}[10]$, and availability of oxygen [11, 12] during fermentation are crucial factors responsible for the formation 
of high levels of TFs. The plucking standards of tea leaves also influence the quality of black tea. The TF content, colour, and sensory evaluation decreased with coarse plucking standard in clone 6/8 [13].

In China, the consumption of black tea beverage accounted for more than $40 \%$ of the total amount (14 million tons) of tea beverage produced in 2011 [14]. The traditional black tea beverages were produced through extraction of processed black tea leaves. Recently, a novel technique was developed for the production of instant black tea powder by fermentation of fresh tea leaves [15]. This new method has the advantage of lower energy consumption and is a more controllable process that results in better quality of the products than the traditional process. In China, some factories are trying to produce instant tea powder and tea beverage with fresh tea leaves. However, this method still needs to be improved for the production of black tea beverage. The present study investigated the effect of fermentation conditions (fermentation temperature, time, and $\mathrm{pH}$ ) and the plucking standard of tea leaves on the chemical components and sensory quality of the fermented juice.

\section{Materials and Methods}

2.1. Materials. Fresh shoots (including one leaf and a bud (mono-leaf), two leaves and a bud (di-leaves), three leaves and a bud (tri-leaves), and four leaves and a bud (quadleaves)) from tea plants (Camellia sinensis (L.) O. Kuntze cv. Yingshuang) were harvested in June 2012 from the tea garden of the Tea Research Institute of Chinese Academy of Agricultural Sciences. Three leaves and a bud were used in the experiments for examining the influence of fermentation temperature, time, and $\mathrm{pH}$ on the chemical components and sensory quality of fermented juice.

2.2. Fermentation Process. The plucked fresh tea shoots were loaded in a withering trough at the rate of $6 \mathrm{~kg} \cdot \mathrm{m}^{-2}$. Ambient air was passed through the leaves for $14 \mathrm{~h}$ to bring about appropriate physical and chemical withering. The withered leaves $(600 \mathrm{~g})$, with $62 \%$ water content (w/w), were crushed with a crusher for 4 min after adding distilled water $(6 \mathrm{~L})$. The mixture of crushed leaves and juice was fermented in a fermenter (Model Labfors-13L, Infors AG, Switzerland) at specific temperatures $\left(25,30,35\right.$, and $\left.40^{\circ} \mathrm{C}\right)$ and $\mathrm{pH}(4.3,4.7$, 5.1 , and 5.5) for $180 \mathrm{~min}$. The $\mathrm{pH}$ of the fermentation system was adjusted with hydrochloric acid solution. During fermentation, oxygen gas was introduced into the fermentation system at a rate of $1.0 \mathrm{~m}^{3} \cdot \mathrm{h}^{-1}$. The fermented products were sampled after specific time intervals from 0 to $180 \mathrm{~min}$, and oxidative enzymes were inactivated by heating to approximately $90^{\circ} \mathrm{C}$ with a microwave applicator (M1-L213B, Midea Group, Guangzhou), which caused the inactivation of the enzymes responsible for the oxidation reactions. Subsequently, the product was subjected to centrifugation in a laboratory centrifuge at $10,000 \mathrm{rpm}$ for $15 \mathrm{~min}$ in order to remove the colloidal and other suspended solid particles which cause turbidity in the tea brew. Finally, the fermented juice was prepared for analysis of chemical components and sensory quality. Fresh shoots with different plucking standards were also freeze-dried for analysis of their chemical components. Each treatment was replicated three times.

2.3. HPLC Analysis of Chemical Components in Fermented Juice. Analyses of catechins, caffeine, gallic acid, and TFs were performed by HPLC [16] using a Model Shimadzu LC-2010A HPLC system (Shimadzu Corporation, Kyoto, Japan). The tea infusion was filtered through a $0.2 \mu \mathrm{m}$ Millipore filter before injection. The HPLC conditions were as follows: injection volume, $10 \mu \mathrm{L}$; column, $5 \mu \mathrm{m}$ Diamonsil TM C18 $(4.6 \mathrm{~mm} \times 250 \mathrm{~mm})$; column temperature, $40^{\circ} \mathrm{C}$; mobile phase A, acetonitrile/acetic acid/water (6:1:193); mobile phase B, acetonitrile/acetic acid/water (60:1:139); gradient, $100 \%$ mobile phase A to $100 \%$ mobile phase B via linear gradient during the first $45 \mathrm{~min}$ and then $100 \%$ mobile phase $B$ up to $60 \mathrm{~min}$; flow rate, $1 \mathrm{~mL} \cdot \mathrm{min}^{-1}$; detector, Shimadzu SPD ultraviolet detector (Shimadzu Corporation, Kyoto, Japan) at $280 \mathrm{~nm}$.

2.4. Spectrophotometric Measurements of TRs and Total Free Amino Acids. TRs were determined using the method described by Roberts and Smith [17], which was subsequently modified by Ngure et al. [18]. The content of free amino acids in the fermented juice was determined with the ninhydrin dying method [19] using glutamic acid as a standard.

2.5. Analysis of PPO and POD Activities. Fresh tea leaves $(0.5 \mathrm{~g})$ were homogenized in $10 \mathrm{~mL}$ of $0.05 \mathrm{M}$ phosphate buffer and $0.3 \mathrm{~g}$ of polyvinyl polypyrrolidone (PVPP) using a mortar and pestle at $4^{\circ} \mathrm{C}$. The homogenate was left to extract at $4^{\circ} \mathrm{C}$ for $12 \mathrm{~h}$ and then centrifuged at $19000 \mathrm{~g}$ for $15 \mathrm{~min}$ to collect the enzyme extracts. PPO activity was assayed according to the method of Dong et al. by evaluating the extent of oxidation of brenzcatechin [20]. The increase in UV-Vis absorbance at $460 \mathrm{~nm}$ was recorded for $10 \mathrm{~min}$. One unit of enzyme activity was calculated as the increase of 0.001 unit of absorbance per minute. POD activity in tea leaves was determined according to the method of Li et al. [21]. The assay mixture consisted of $0.05 \mathrm{M}$ sodium phosphate buffer ( $\mathrm{pH} 7.0$ ), $0.012 \mathrm{M} \mathrm{H}_{2} \mathrm{O}_{2}$, $0.07 \mathrm{M}$ guaiacol, and $0.1 \mathrm{~mL}$ of the enzyme solution in a final volume of $3.0 \mathrm{~mL}$. The increase in absorbance at $470 \mathrm{~nm}$ was recorded for $4 \mathrm{~min}$. One unit of enzyme activity was calculated as the increase of 0.01 unit of absorbance per minute.

2.6. Sensory Evaluation. Fermented juices were scored by a professional team of ten experts in tea quality evaluation from the Tea Research Institute of the Chinese Academy of Agricultural Sciences. The taste and colour of the fermented juices were scored by each member of the team. The ninepoint hedonic scale was used $(9=$ extreme like, $5=$ neutral, $1=$ extreme dislike) for scoring. The scores of the taste and colour were integrated into the acceptability score [22].

2.7. Statistical Analysis. Results are expressed as a mean of three replicates. Analysis of variance and significant differences among means were performed with one-way ANOVA using 


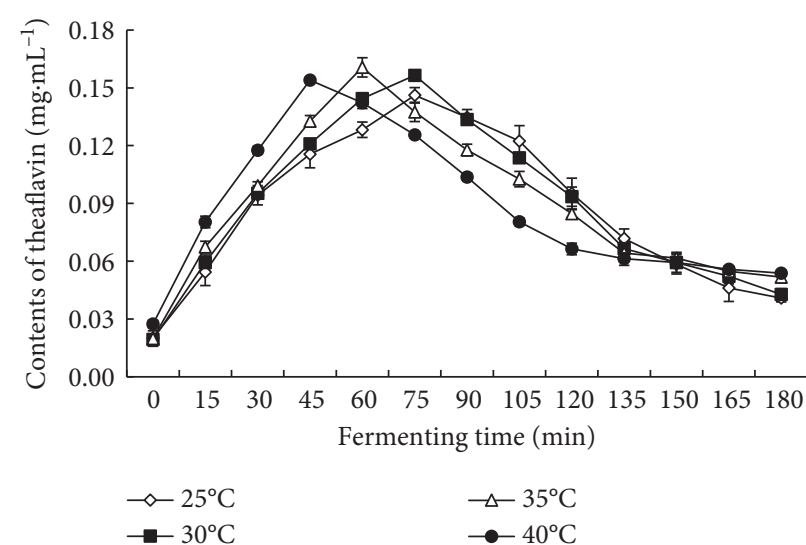

(a)

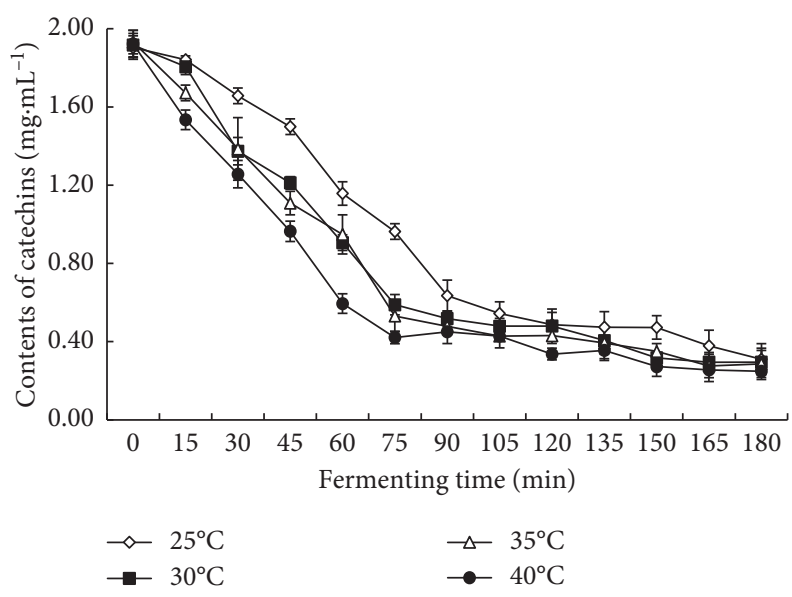

(c)

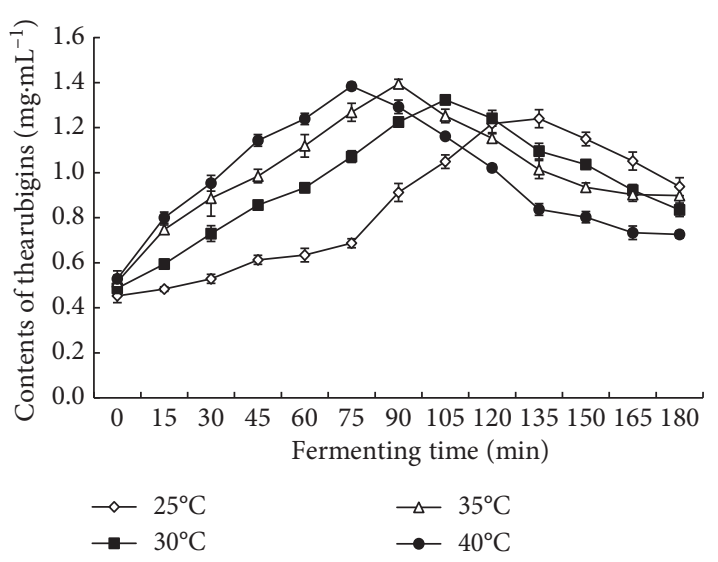

(b)

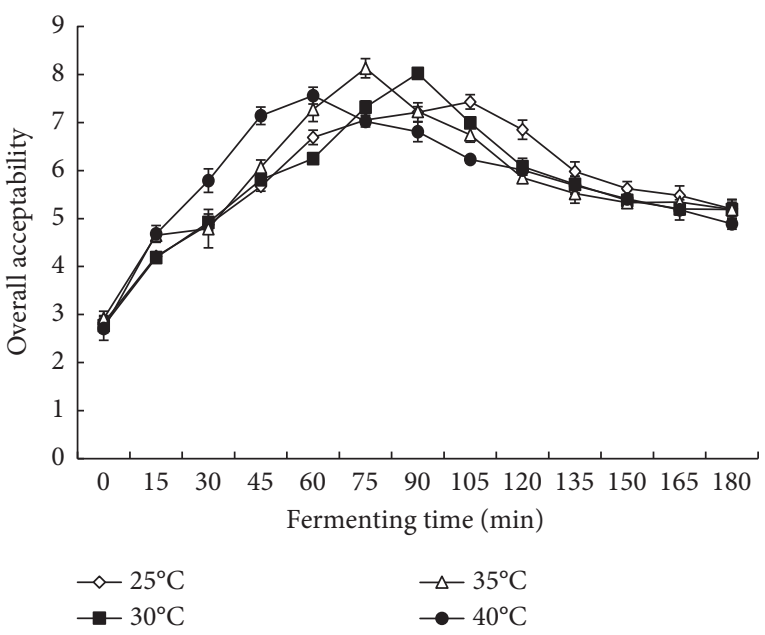

(d)

Figure 1: Effect of fermentation time and temperature on the concentrations of (a) theaflavins, (b) thearubigins, (c) catechins, and (d) the overall acceptability of fermented juices $(n=3)$.

SPSS 16.5 (IBM, Armonk, NY). Correlation analysis was also performed using SPSS 16.5.

\section{Results and Discussion}

3.1. Effect of Fermentation Time and Temperature on the Contents of Chemical Components and Sensory Quality of Fermented Juice. During fermentation, catechins are oxidized to $o$-quinones (highly unstable form) by PPO, and they react to form TFs and TRs [3]. It was found that the formation of TFs increased with time during the early stages of fermentation (Figure 1(a)). As the fermentation progressed, the concentration of TFs reached a maximum and then slowly declined. The time at which the maximum amounts of TFs had formed was defined as the optimum fermentation time for the given temperature. A similar evaluation criterion of optimum fermentation was also reported in black tea manufacture $[23,24]$. The contents of TFs were found to have good correlation coefficients with taste quality [23], and the quality of Turkish black tea was also related to the contents of TFs [24]. These experimental results showed that the optimum fermentation time under different fermentation temperatures was variable. When the fermentation temperature was decreased, the optimum fermentation time was delayed. The optimum fermentation time at $40,35,30$, and $25^{\circ} \mathrm{C}$ was $45,60,75$, and $75 \mathrm{~min}$, respectively. The significant relationship between fermentation time and temperature and the influence of these parameters on the formation of TFs and the sensory quality of black tea have been previously reported [9]. Maintaining a low fermentation temperature and short time ensured lesser conversion of (-)-epicatechin gallate (ECG) and (-)-epigallocatechin gallate (EGCG) and favoured the formation of simple theaflavins $[9,25]$. In this study, the concentration of TFs in fermented juices processed at 30 and $35^{\circ} \mathrm{C}$ was higher than that in the fermented juice processed at $40^{\circ} \mathrm{C}$. So, lower temperatures $\left(25-35^{\circ} \mathrm{C}\right)$ may be more suitable for the formation of TFs in the fermented juice.

Increasing the fermentation temperature can increase the rate of enzymatic oxidation which may lead to a faster depletion of all catechins. During fermentation, the concentrations of catechins in fermented juice gradually decreased (Figure 1(c)), 
TABLE 1: Effect of $\mathrm{pH}$ on the concentrations of different chemical components $\left(\mathrm{mg} \cdot \mathrm{mL}^{-1}\right)$ and overall acceptability of fermented juices.

\begin{tabular}{|c|c|c|c|c|c|c|c|}
\hline $\mathrm{pH}$ & $\begin{array}{c}\text { Overall acceptability } \\
\text { score }\end{array}$ & $\begin{array}{c}\text { Gallic } \\
\text { acid }\end{array}$ & Caffeine & $\begin{array}{c}\text { Amino } \\
\text { acids }\end{array}$ & Catechins & TFs & TRs \\
\hline 4.3 & $5.73^{\mathrm{a}}$ & $0.13^{\mathrm{a}}$ & $0.87^{\mathrm{a}}$ & $0.62^{\mathrm{b}}$ & $1.21^{\mathrm{a}}$ & $0.24^{\mathrm{a}}$ & $0.92^{\mathrm{a}}$ \\
\hline 4.7 & $5.88^{\mathrm{a}}$ & $0.17^{\mathrm{b}}$ & $0.88^{\mathrm{a}}$ & $0.57^{\mathrm{c}}$ & $1.17^{\mathrm{a}}$ & $0.21^{\mathrm{b}}$ & $0.96^{\mathrm{a}}$ \\
\hline 5.1 & $6.86^{\mathrm{b}}$ & $0.17^{\mathrm{b}}$ & $0.89^{\mathrm{a}}$ & $0.52^{\mathrm{d}}$ & $0.91^{\mathrm{b}}$ & $0.18^{\mathrm{c}}$ & $1.21^{\mathrm{b}}$ \\
\hline 5.5 & $6.51^{c}$ & $0.24^{\mathrm{c}}$ & $0.98^{\mathrm{b}}$ & $0.66^{\mathrm{a}}$ & $0.85^{\mathrm{c}}$ & $0.16^{\mathrm{d}}$ & $1.42^{\mathrm{c}}$ \\
\hline
\end{tabular}

a,b,c,d Significant differences at the level $p<0.05$.

although the rate of this decrease was different at different temperatures. When the fermentation temperature was increased, the concentrations of catechins in fermented juice decreased faster. These changes were similar to those observed in traditional black tea fermentation; that is, TFs are continuously formed or oxidized during fermentation, and the oxidation of TFs becomes predominant as the substrate catechins are oxidized [26].

The formation of TRs was also found to be influenced by the fermentation temperature and time (Figure 1(b)). Oxidative degradation of TFs and polymerization of the degradation products resulted in the formation of thearubigins (TRs) [27]. The formation of TRs increased with time during the early stages of fermentation. As the fermentation progressed, TRs reached a maximum and then declined slowly. However, the time at which TRs reached the maximum value was later compared to TFs. However, the decrease in the amount of TFs was more rapid than that of TRs, and while ca. $70 \%$ of the TFs decreased during the second stage (90-180 $\mathrm{min}$ ) of the fermentation, only $35 \%$ of the TRs underwent degradation in the same time.

Figure 1(d) shows the overall acceptability of the fermented juices during fermentation at different temperatures. During the first stage $(0-75 \mathrm{~min})$ of the fermentation, the scores of overall acceptability increased sharply and then decreased gently during the rest of the fermentation process. The top scores of overall acceptability are influenced by the temperature and time of the fermentation. The fermented juices at $35^{\circ} \mathrm{C}$ had the highest scores, followed by the scores at 30 and $40^{\circ} \mathrm{C}$, while the score at $25^{\circ} \mathrm{C}$ was the lowest. When the maximum scores of overall acceptability for various fermentation temperatures were compared, it was obvious that the optimum fermentation time was shorter at higher temperatures than that at lower temperatures. The fermentations performed at 30 and $35^{\circ} \mathrm{C}$ resulted in juices which had the best sensory quality at 90 and 75 min of fermentation time, respectively. While the concentrations of TFs $(r=0.84, p<0.01)$ were found to be highly positively correlated to the overall acceptability scores of the fermented juices, the TRs/TFs values $(r=-0.59, p<0.05)$ were negatively correlated to the scores. A high overall acceptability score of the fermented juices showed TRs/TFs in the range of 8-10, which was less than the range of 10-12 for excellent black tea [28]. Ideal fermentation produces a proper balance between the concentrations of TFs and TRs, and these substances of the fermented juice are responsible for its liquoring characteristics [15]. Based on the overall acceptability and chemical index (concentration of TFs), the optimum temperature and time of fermented juices for black tea beverage were concluded to be $35^{\circ} \mathrm{C}$ and $75 \mathrm{~min}$, respectively.
3.2. Effect of pH on the Contents of Chemical Components and Sensor Quality of Fermented Juices. The $\mathrm{pH}$ value may be an important factor that influences the formation of TFs during the fermentation process. Cloughley and Ellis [10] reported that adjusting the $\mathrm{pH}$ value of fermenting tea leaves from the physiological status ( $\sim \mathrm{pH} 5.5)$ to $\mathrm{pH} 4.5-4.8$ resulted in an increase in the content of TFs and a decrease of TRs, which is sufficient to increase the score of the organoleptic evaluation of central African black tea. Mao et al. [29] have reported that the $\mathrm{pH}$ value $(4.0-7.0)$ of the fermentation system showed remarkably negative correlation to TFs $(r=-0.967, p<0.01)$ and TRs $(r=-0.864, p<0.01)$. Based on the experiments in this study, a lower $\mathrm{pH}$ benefited the formation of TFs and simultaneously restricted the formation of TRs (Table 1). By increasing the $\mathrm{pH}$ value from 4.3 to 5.5 , the content of TFs decreased gradually from $0.24 \mathrm{mg} \cdot \mathrm{mL}^{-1}$ to $0.16 \mathrm{mg} \cdot \mathrm{mL}^{-1}$, while the content of TRs increased from $0.92 \mathrm{mg} \cdot \mathrm{mL}^{-1}$ to $1.42 \mathrm{mg} \cdot \mathrm{mL}^{-1}$ in fermented juices. The highest score of overall acceptability was obtained at $\mathrm{pH} 5.1$ even though the TF content was not at the highest level. The lower overall acceptability score at lower $\mathrm{pH}$ was mainly due to the higher content of remaining catechins which might also increase the astringency, especially (-)-epicatechin gallate (ECG) and (-)-epigallocatechin gallate (EGCG) [10].

3.3. Effect of the Plucking Standard of Tea Leaves on the Content of Different Chemical Components and Sensory Quality of Fermented Juice. Fresh tea leaves with different plucking standards were fermented in order to evaluate their effect on the contents of chemical components and sensory quality of fermented juice. Table 2 shows the results. The overall acceptability scores of the fermented juices made of samples of mono-leaf or di-leaves were much lower than those of the fermented juices derived from samples of triand quad-leaves. However, there was no significant difference in the overall acceptability score between the fermented juices of the latter two samples. The contents of catechins, amino acids, and caffeine in the fermented juices made from the samples of mono-leaf to quad-leaves generally tended to decrease while the contents of TFs in the fermented juices increased. Furthermore, there were high positive correlations between the overall acceptability scores and the content of TFs $(r=0.98, p<0.01)$.

TFs are the components of black tea infusion that have a significant influence on the quality of black tea [30]. The different monomers of TFs, including TF, TF-3-G, TF-3'-G, and TFDG, are formed by different parent flavanols [31]; that is, TF is obtained from (-)-epicatechin (EC) and 
TABLE 2: Overall acceptability and the concentrations of different chemical components $\left(\mathrm{mg} \cdot \mathrm{mL}^{-1}\right)$ of the fermented juices derived from fresh tea leaves with different plucking standards.

\begin{tabular}{|c|c|c|c|c|c|c|}
\hline Tea leaves & $\begin{array}{l}\text { Overall acceptability } \\
\text { score }\end{array}$ & Caffeine & Amino acids & Catechins & TFs & TR \\
\hline Mono-leaf & $6.48^{\mathrm{a}}$ & $0.60^{\mathrm{a}}$ & $0.52^{\mathrm{a}}$ & $0.91^{\mathrm{a}}$ & $0.136^{\mathrm{a}}$ & $1.39^{\mathrm{a}}$ \\
\hline Di-leaves & $6.69^{\mathrm{b}}$ & $0.55^{\mathrm{b}}$ & $0.47^{\mathrm{b}}$ & $0.90^{\mathrm{a}}$ & $0.127^{\mathrm{a}}$ & $1.20^{\mathrm{b}}$ \\
\hline Tri-leaves & $7.87^{\mathrm{c}}$ & $0.47^{\mathrm{C}}$ & $0.41^{\mathrm{c}}$ & $0.86^{\mathrm{b}}$ & $0.206^{\mathrm{b}}$ & $1.70^{\mathrm{c}}$ \\
\hline Quad-leaves & $7.79^{c}$ & $0.41^{\mathrm{d}}$ & $0.43^{\mathrm{c}}$ & $0.77^{\mathrm{c}}$ & $0.211^{\mathrm{b}}$ & $1.75^{\mathrm{c}}$ \\
\hline
\end{tabular}

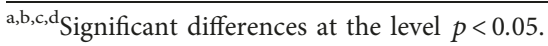

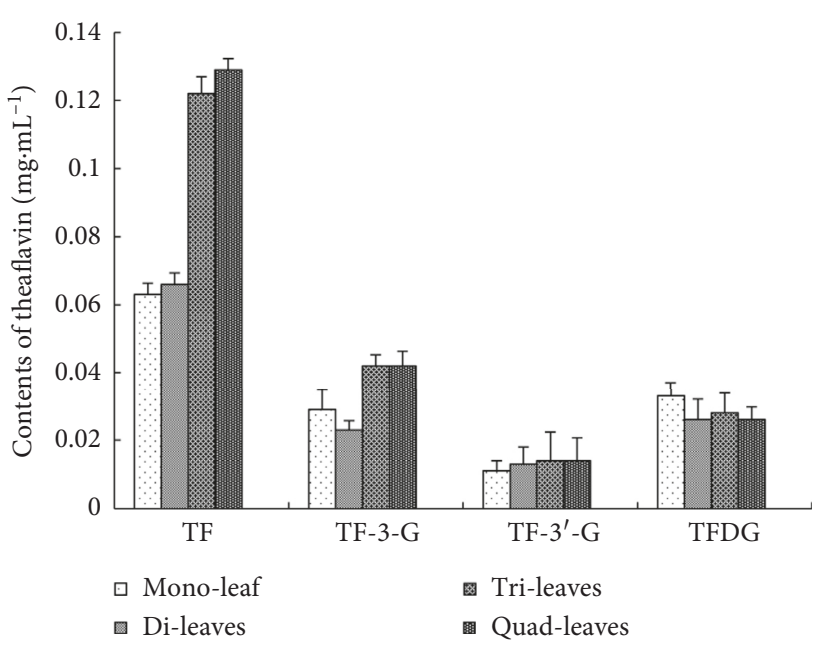

Figure 2: Effect of the plucking standard of fresh tea leaves on the TF concentrations of fermented juices $(n=3)$.

TABle 3: Content of catechins (\%) in fresh tea leaves with different plucking standards.

\begin{tabular}{lccccc}
\hline Tea leaves & EGC & EGCG & EC & ECG & Total catechins \\
\hline Mono-leaf & $0.95^{\mathrm{a}}$ & $4.84^{\mathrm{a}}$ & $0.38^{\mathrm{a}}$ & $0.68^{\mathrm{a}}$ & $8.46^{\mathrm{a}}$ \\
Di-leaves & $1.24^{\mathrm{b}}$ & $3.84^{\mathrm{b}}$ & $0.42^{\mathrm{b}}$ & $0.52^{\mathrm{b}}$ & $7.24^{\mathrm{b}}$ \\
Tri-leaves & $1.34^{\mathrm{c}}$ & $3.46^{\mathrm{c}}$ & $0.44^{\mathrm{c}}$ & $0.46^{\mathrm{c}}$ & $6.88^{\mathrm{c}}$ \\
Quad-leaves & $1.60^{\mathrm{d}}$ & $3.18^{\mathrm{d}}$ & $0.41^{\mathrm{b}}$ & $0.43^{\mathrm{d}}$ & $6.17^{\mathrm{d}}$ \\
\hline
\end{tabular}

${ }_{\mathrm{a}, \mathrm{b}, \mathrm{c}, \mathrm{d}}$ Significant differences at the level $p<0.05$.

(-)-epigallocatechin (EGC), TF-3-G from EC and EGCG, TF- $3^{\prime}-\mathrm{G}$ from ECG and EGC, and TFDG from ECG and EGCG. In the fermented juices, TF was the major compound of all TFs (Figure 2), accounting for about 50\% (46.3-61.1\%) of the total TFs, which was much higher than the amounts of TFDG (12.3-24.3\%) and TF-3-G (18.1-21.3\%), while TF-3'G was only $6.6-10.2 \%$ of the total content of TFs. Fermented juices made of the samples of tri- and quad-leaves contained a higher proportion of TF (59.2\% and $61.1 \%$, resp.), compared with those from the samples of mono-leaf and dileaves. Table 3 shows the constituents of catechins in the fresh tea leaves of different plucking standards. In the fermentation juices made of mono-leaf to quad-leaves, the contents of EGCG and ECG decreased, while the content of EGC increased. The high contents of EGC and EC in tri- and quad-leaves are likely responsible for the high TF content in the fermented juice since TF is formed from EC and EGC.

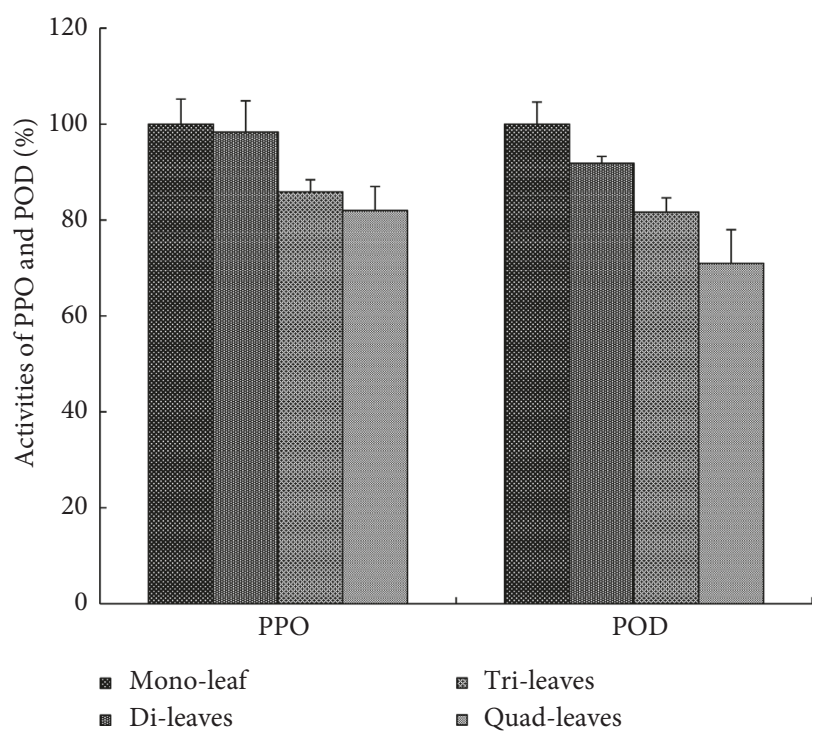

FIgURE 3: PPO and POD activities of fresh tea leaves with different plucking standards $(n=3)$.

During fermentation, catechins are oxidized by PPO and POD to form TFs and TRs [7]. The different contents of TFs in fermented juices are a result of the activities of enzymes (PPO and POD) and the constituents of catechins. Based on the data in Figure 3, it is evident that the PPO and POD activities of fresh tea leaves gradually decreased from the samples of mono-leaf to quad-leaves, although there was no significant difference between the samples of tri-leaves and quad-leaves in this regard. The lower POD activities in older fresh tea leaves of the samples of tri-leaves and quad-leaves limited the oxidation of TFs and retained higher concentration of TFs in fermented juices. However, the amount of TFs in fermented tea juice was not significantly influenced by the activity of PPO. Consequently, the fermented juices made of the samples of tri-leaves and quad-leaves exhibited higher contents of TFs than those of the samples of monoleaf to di-leaves.

\section{Conclusion}

The present study investigated the effect of fermentation conditions and the plucking standard of fresh tea leaves on the chemical components and sensory quality of fermented juice. On the basis of the analyses of the chemical components and the overall acceptability of fermented juices, the optimum parameters for the fermentation process were 
determined to be a temperature of $35^{\circ} \mathrm{C}$, time duration of $75 \mathrm{~min}$, and $\mathrm{pH}$ 5.1. One bud and three leaves (tri-leaves) and one bud and four leaves (quad-leaves) were better materials for the production of fermented juice than one bud and one leaf (mono-leaf) and one bud and two leaves (di-leaves). These results provide the practical information for processing fermented tea juice, which is used for the production of black tea beverage by fermentation of fresh tea leaves. Tea processors can process fermented juice with higher TFs and better sensory quality than black tea processed with conventional methods.

\section{Conflicts of Interest}

The authors declare that there are no conflicts of interest regarding the publication of this paper.

\section{Authors' Contributions}

Ping Tang and Dan-Yu Shen contributed equally to this work.

\section{Acknowledgments}

This research was supported by the Hangzhou Agricultural Scientific Research Project (20160432B25) and the Central Level, Scientific Research Institutes for Basic R\&D Special Fund Business (Y2016PT40 and Y2016CG13).

\section{References}

[1] C. S. Yang and J. M. Landau, "Effects of tea consumption on nutrition and health," Journal of Nutrition, vol. 132, no. 10, pp. 2409-2412, 2002.

[2] A. B. Sharangi, "Medicinal and therapeutic potentialities of tea (Camellia sinensis L.)-a review," Food Research International, vol. 42, no. 5-6, pp. 529-535, 2009.

[3] M. G. Hampton, Edited by K. C. Wilson and M. N. Clifford, Eds., Chapman \& Hall, London, UK, 1992.

[4] P. O. Owuor and M. Obanda, "The changes in black tea quality due to variations of plucking standard and fermentation time," Food Chemistry, vol. 61, no. 4, pp. 435-441, 1998.

[5] K. M. M. John, M. Thiruvengadam, G. Enkhtaivan, and D. H. Kim, "Variation in major phenolic compounds and quality potential of CTC black tea elicited by Saccharomyces cercevisiae, and its correlation with antioxidant potential," Industrial Crops and Products, vol. 55, no. 6, pp. 289-294, 2014.

[6] C. L. Lin, H. C. Huang, and J. K. Lin, “Theaflavins attenuate hepatic lipid accumulation through activating AMPK in human HepG2 cells," Journal of Lipid Research, vol. 48, no. 11, pp. 2334-2343, 2007.

[7] C. Someswararao and P. P. Srivastav, "A novel technology for production of instant tea powder from the existing black tea manufacturing process," Innovative Food Science and Emerging Technologies, vol. 16, no. 39, pp. 143-147, 2012.

[8] M. Obanda, P. O. Owuor, and R. Mang'oka, "Changes in the chemical and sensory quality parameters of black tea due to variations of fermentation time and temperature," Food Chemistry, vol. 75, no. 4, pp. 395-404, 2001.

[9] P. O. Owuor and M. Obanda, "Comparative responses in plain black tea quality parameters of different tea clones to fermentation temperatures and durations," Food Chemistry, vol. 72, no. 3, pp. 319-327, 2001.

[10] J. B. Cloughley and R. T. Ellis, "The effect of $\mathrm{pH}$ modification during fermentation on the quality parameters of Central African black teas," Journal of the Science of Food and Agriculture, vol. 31, no. 9, pp. 924-934, 1980.

[11] P. O. Owuor and M. Obanda, "Effects of fermentation under enriched oxygen atmosphere on clonal black tea aroma complex," Food Science and Technology Research, vol. 4, no. 2, pp. 136-139, 1998.

[12] P. O. Owuor and M. Obanda, "Influence of enriched oxygen atmosphere during fermentation on plain clonal black tea quality parameters development," Tropical Science, vol. 38, pp. 165-170, 1998.

[13] P. O. Owuor, M. A. Obanda, C. O. Othieno, H. Horita, T. Tsushida, and T. Murai, "Changes in chemical composition and quality of black tea due to plucking standards," Agricultural and Biological Chemistry, vol. 51, no. 12, pp. 3383-3384, 1987.

[14] Z. M. Chen, "Advance in comprehensive utilization of tea resource," in Proceeding of 2012 International (Hangzhou) Symposium on Comprehensive Utilization of Tea Resource, pp. 1-5, Zhejiang University Press, Hangzhou, China, 2013.

[15] V. R. Sinija, H. N. Mishra, and S. Bal, "Process technology for production of soluble tea powder," Journal of Food Engineering, vol. 82, no. 3, pp. 276-283, 2007.

[16] Y. Liang, J. Lu, L. Zhang, S. Wu, and S. Wu, "Estimation of black tea quality by analysis of chemical composition and colour difference of tea infusion," Food Chemistry, vol. 80, no. 2, pp. 283-290, 2003.

[17] E. H. Roberts and R. Smith, "Phenolic substances of manufactured tea. II. Spectrophotometric evaluation of tea liquors," Journal of the Science of Food and Agriculture, vol. 14, pp. 689-700, 1983.

[18] F. M. Ngure, J. K. Wanyoko, S. M. Mahungu, and A. A. Shitandi, "Catechins depletion patterns in relation to theaflavin and thearubigins formation," Food Chemistry, vol. 115, no. 1, pp. 8-14, 2009.

[19] Y. Q. Xu, X. Y. Zhong, J. F. Yin, H. B. Yuan, P. Tang, and Q. Z. Du, "The impact of $\mathrm{Ca}^{2+}$ combination with organic acids on green tea infusions," Food Chemistry, vol. 139, no. 1-4, pp. 944-948, 2013.

[20] H. Dong, L. Cheng, J. Tan, K. Zheng, and Y. Jiang, "Effects of chitosan coating on quality and shelf life of peeled litchi fruit," Journal of Food Engineering, vol. 64, no. 3, pp. 355-358, 2004.

[21] B. Li, Y. Du, X. Liang, X. Wang, X. Wang, and J. Yang, "Effect of chitosan coating on respiratory behaviour and quality of stored litchi under ambient temperature," Journal of Food Engineering, vol. 102, no. 1, pp. 94-99, 2011.

[22] S. Ibanoglu, P. Ainsworth, E. A. Ozer, and A. Plunkett, "Physical and sensory evaluation of a nutritionally balanced gluten-free extruded snack," Journal Food Engineering, vol. 75, no. 4, pp. 469-472, 2006.

[23] P. O. Owuor and S. G. Reeves, "Optimizing fermentation time in black tea manufacture," Food Chemistry, vol. 21, no. 3, pp. 195-203, 1986.

[24] M. Tüfekci and S. Güner, "The determination of optimum fermentation time in Turkish black tea manufacture," Food chemistry, vol. 60, no. 1, pp. 53-56, 1997.

[25] P. O. Owuor and M. Obanda, "Fermentation temperature and duration effects on black tea quality," Tea, vol. 14, pp. 21-30, 1993. 
[26] A. Robertson, "Effects of physical and chemical conditions on the in vitro oxidation of tea leaf catechins," Phytochemistry, vol. 22, no. 4, pp. 897-903, 1983.

[27] J. Wherkoven, Tea Processing. FAO Agricultural Bulletin No. 26, FAO and The United Nations, Rome, Italy, 1974.

[28] A. Robertson, "The chemistry and biochemistry of black tea production, the non-volatiles," in Tea: Cultivation to Consumption, K. C. Wilson and M. N. Clifford, Eds., Chapman and Hall, London, UK, 1992.

[29] Q. Mao, Q. Zhu, Z. Liu, and Z. Shi, "Effects of $\mathrm{pH}$ modification on activity of polyphenol oxidases and formation of theaflavins," Journal of Hunan Agricultural University, vol. 31, no. 5, pp. 524-526, 2005.

[30] P. O. Owuor and M. Obanda, "The use of green tea (Camellia sinensis) leaf flavan-3-ol composition in predicting plain black tea quality potential," Food Chemistry, vol. 100, no. 3, pp. 873-884, 2007.

[31] N. Subramanian, P. Venkatesh, S. Ganguli, and V. P. Sinkar, "Role of polyphenol oxidase and peroxidase in the generation of black tea theaflavins," Journal of Agricultural and Food Chemistry, vol. 47, no. 7, pp. 2571-2578, 1999. 

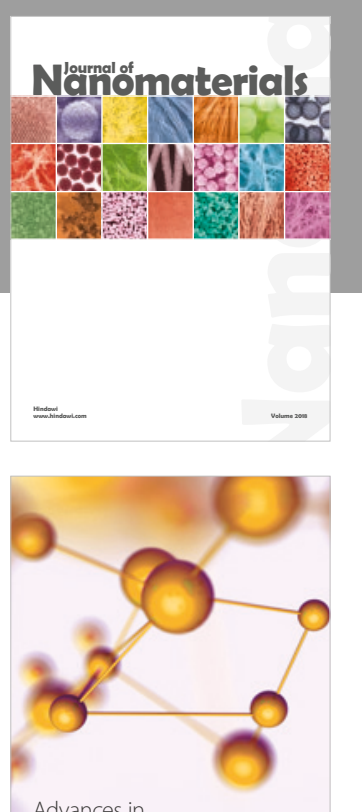

Physical Chemistry
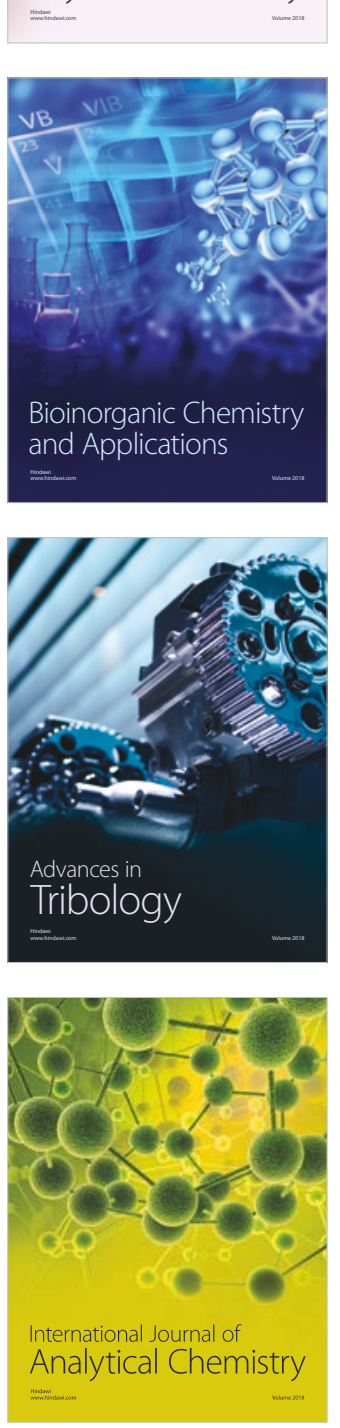

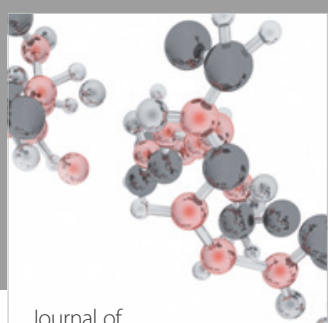

Analytical Methods

in Chemistry

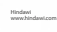

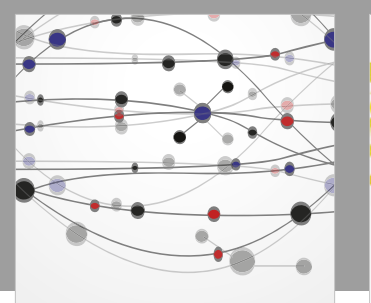

The Scientific World Journal

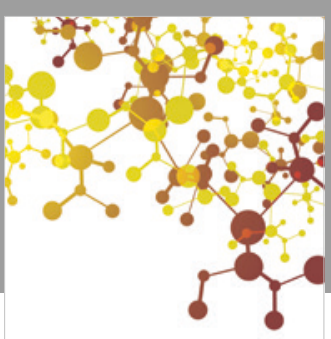

Journal of

Applied Chemistry
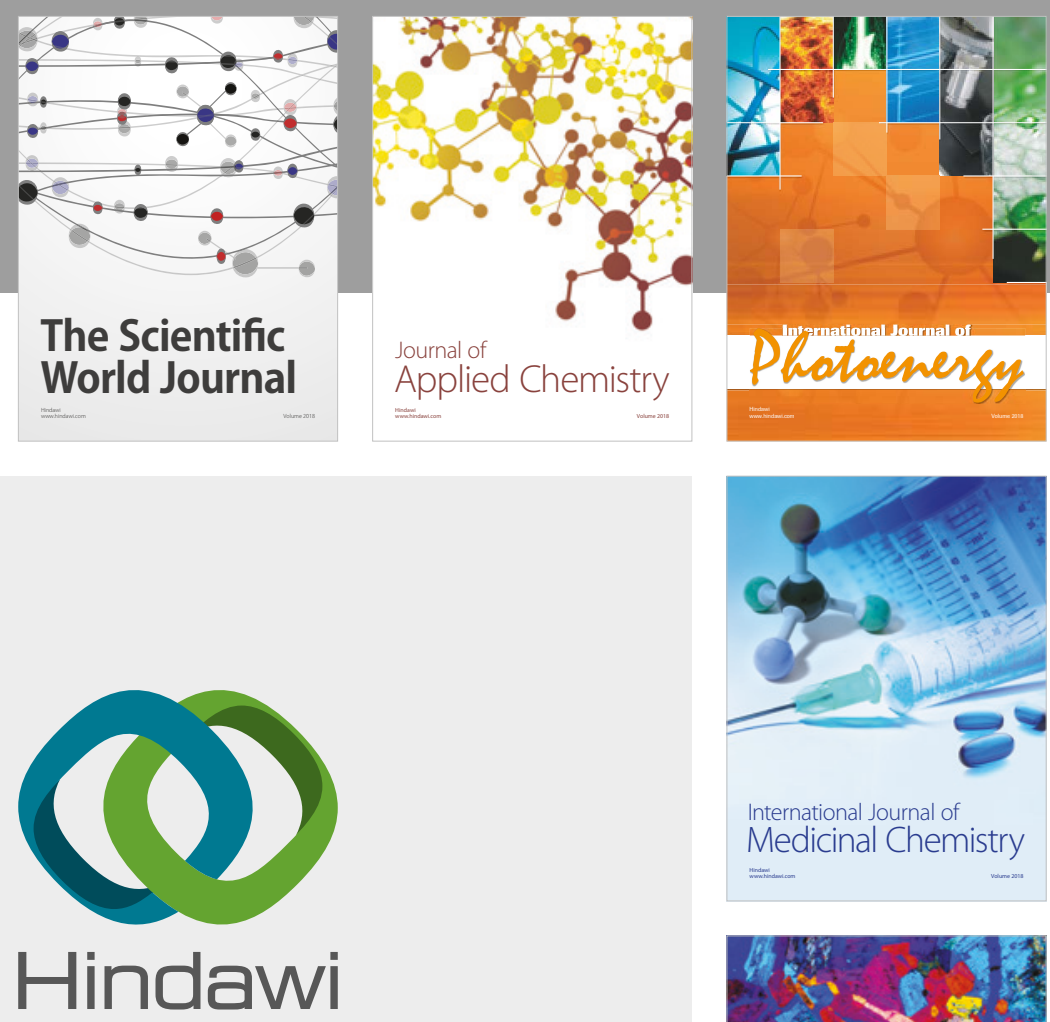

Submit your manuscripts at

www.hindawi.com
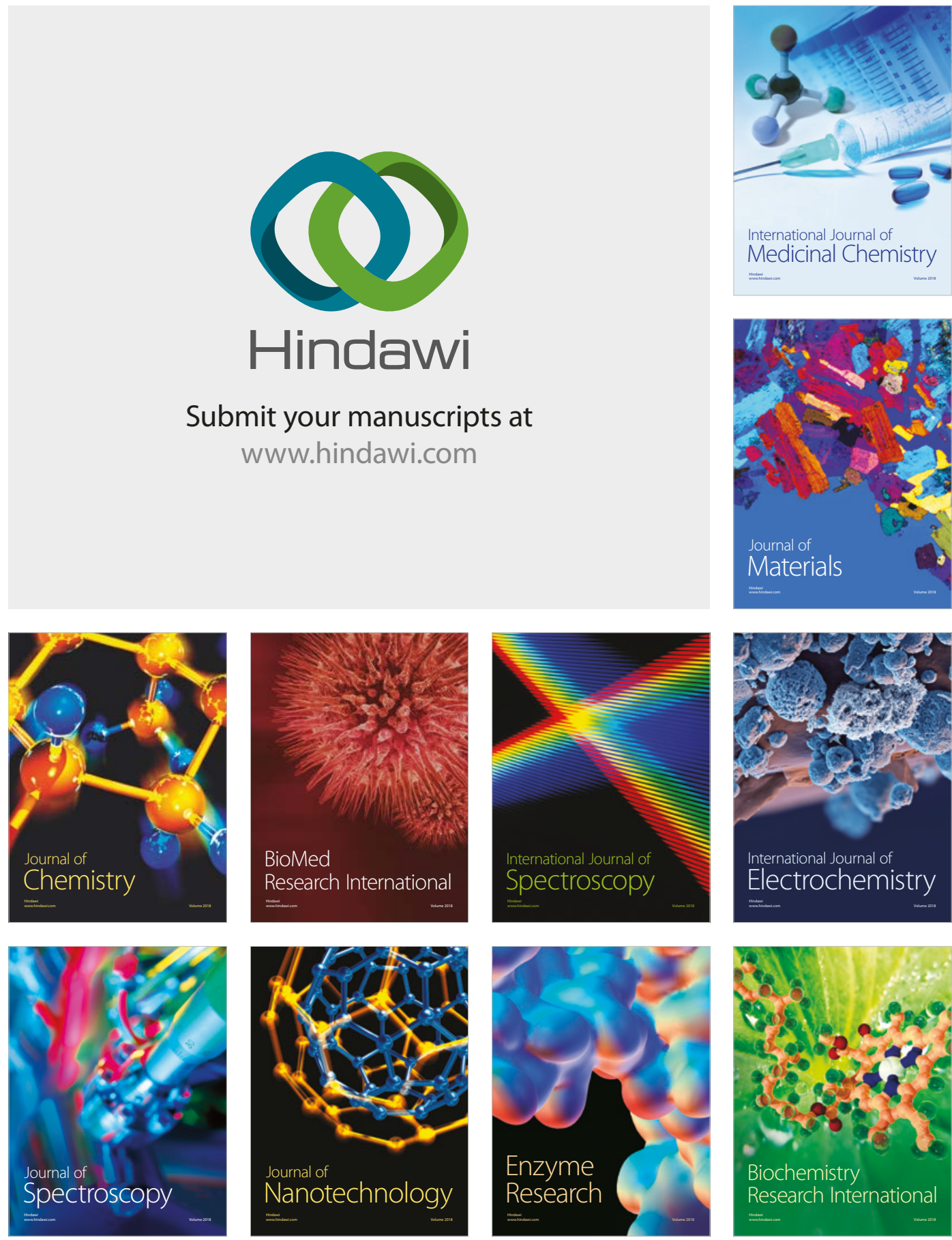
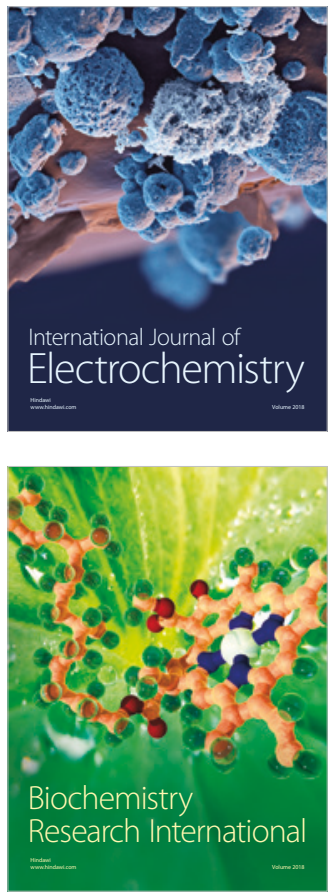